\title{
A study of satisfaction with dental services among adults in the United Kingdom
}

\author{
A study of satisfaction with dental services among adults in the United Kingdom.
}

R. Bedi, N. Gulati and C. McGrath Br Dent J 2005; 198: 433-437

Objectives

To determine satisfaction with dental care services among the UK adult population, and to assess their knowledge regarding the dental complaints procedure.

Methods

A national survey involving a multi-stage random sampling procedure with face-to-face home interviews of 5,385 UK residents was conducted in 1999.

\section{Results}

The response rate was 69\% and 3,739 adults took part in this study. Majority of people (89\%) were satisfied with the quality of care they received. Only 2\% (76) had actually complained, although 10\% (388) had felt like complaining in the past. One third $(32 \%, 1,188)$ did not know to whom to complain if they had a problem. Among those who knew whom to contact, over a third $(36 \%, 1,359)$ would contact somebody outside the practice, while another third $(31 \%, 1,169)$ would contact their dentist or dental practice.

\section{Conclusion}

Overall most people are satisfied with the quality of dental care they receive. However, 2\% have complained and 10\% have felt like complaining about their dentist/ dental care. In general, knowledge of the complaints procedure and whom to contact appears fragmented.

\section{IN BRIEF}

- A national study of satisfaction about dental services in the UK.

- Most people in Britain are satisfied with dental services. However, about one in ten have felt like or actually have complained about dental services in the past.

- One in three did not know to whom to complain if they were dissatisfied about dental services.

- Knowledge about the complaints procedure process appears fragmented.

\section{COMMENT}

This national study involving face-to-face home interviews concludes that 9 out of 10 adults are satisfied with the quality of care they receive at their dentist. Can we therefore conclude that this reflects a situation where the majority of UK adults are satisfied with their care? This is debatable, since the study is focussed on a single question 'How satisfied are you with the quality of care you receive at the dentist?' and some argue that patient satisfaction is a multi-dimensional phenomena and single question measures are inadequate for assessing the entire concept and raise questions about which facet of satisfaction respondents are rating. ${ }^{1}$ For example, whilst users place a high priority on the dentists' technical skills and pain management, a major source of dissatisfaction is the barrier to access caused by the high cost of treatment and limited availability of NHS services. ${ }^{2}$

The study does show however that some groups are more likely to feel satisfied than others; for example the elderly are more likely to be satisfied with the quality of care than younger adults. This may reflect differences in levels of expectations since patient satisfaction is a subjective concept influenced by the degree of convergence between the expectations patients have of ideal care and their perceptions of the care they really get. ${ }^{3}$

Problem-motivated attenders were found to be least likely to be satisfied with quality of care. The reasons for this merit further study but may be explained by the degree of dissonance between the expectations of these patients and the care provided by the dentist.

It is one thing to feel unhappy about the quality of care received, but it is another to feel so strongly that a complaint is made. The paper points out that receiving a complaint causes a great deal of worry and stress to the dentist, and practitioners will want to know how best to avoid the situation. It is interesting to note that whilst some groups such as private as opposed to NHS patients were shown to be more likely to make complaints, they did not express any lower levels of dissatisfaction with the quality of care. It may be that a degree of empowerment is needed to express dissatisfaction in a complaints process and it would be helpful to investigate this issue further. Understanding why people make complaints helps the practitioner to take steps to prevent the situation from occurring.

1. Oberst M T. Patients' perceptions of care: measurement of quality and satisfaction Cancer 1984; 53: 2366-2373.

2. Calnan M, Dickinson M \& Manley G. The quality of general dental care: public and users; perceptions. Quality health care 1999; 8: 149-153.

3. Risser N L. Development of an instrument to measure patient satisfaction with nurses and nursing care in primary care settings. Nursing Research 1975; 24: 45-52

Dr Rebecca Harris, Senior Lecturer in Dental Public Health,

University of Liverpool

doi: 10.1038/sj.bdj.4812195 